\title{
ENTOMOLOGY
}

\section{The insect antenna: segmentation, patterning and positional homology}

\author{
A. Minelli \\ Department of Biology, University of Padova, Italy
}

\begin{abstract}
The basic mechanism by which the antennal flagellum is subdivided into flagellomeres is probably the same in all insects, irrespective of whether the process occurs in the embryo, in the eye/antenna imaginal disc, or through a series of post-embryonic increments punctuated by moults. The ultimate origin of (all?) flagellomeres is the first antennomere following the pedicel, from which split off in apical direction new primary flagellomeres, each of which is eventually the source of secondary flagellomeres, according to specific spatial and temporal patterns subject to heterochrony. Only a detailed knowledge of the underlying segmentation processes could provide the ultimate background for determining positional homology between flagellomeres of two antennae with different number of antennomeres. The antennae of the Heteroptera are likely re-segmented, as their second antennomere seems to include a flagellar component. The larval antennae of the holometabolans are temporal serial homologues of those of the adult, but their segmental composition is problematic. Significant progress will be done by understanding what differentiates antennomeres that divide, either embryonically or post-embryonically, from those that do not; and by discovering whether the spatial and
\end{abstract}

Correspondence: Alessandro Minelli, Department of Biology, University of Padova, via Ugo Bassi 58B, 35131 Padova, Italy.

E-mail: alessandro.minelli@unipd.it

Key words: Heterochrony; Meriston; Pentatomidae; Positional homology; Resegmentation.

Acknowledgements: the author is grateful to Giuseppe Fusco and to an anonymous referee for their critical comments on a draft version of this article.

Conflict of interest: the author declares no potential conflict of interest.

Received for publication: 2 March 2017.

Revision received: 10 April 2017.

Accepted for publication: 10 April 2017.

(C) Copyright A. Minelli, 2017

Licensee PAGEPress, Italy

Journal of Entomological and Acarological Research 2017; 49:6680

doi:10.4081/jear:2017.6680

This article is distributed under the terms of the Creative Commons Attribution Noncommercial License (by-nc 4.0) which permits any noncommercial use, distribution, and reproduction in any medium, provided the original author(s) and source are credited. temporal pattern of division along the flagellum depends on local cues, or on signals travelling along the whole proximo-distal axis of the appendage.

\section{Introduction}

Three distinct processes are relevant to an assessment of positional homology between specific features, or markers, restricted to one or more antennomeres of an insect antenna (Figure 1): i) the primary proximo-distal patterning into scape, pedicel and flagellum; ii) the segmentation of the flagellum into flagellomeres; iii) the regional patterning of the flagellum, producing specializations such as lateral projections, sensory structures or an apical club involving a restricted number of flagellomeres.

The articulation of the antenna into scape, pedicel and flagellum is nearly universally conserved (but see below); therefore, this level of proximo-distal patterning is generally unproblematic in respect to the assessment of homology between specific antennomeres of two insects. To the contrary, the process by which the flagellum is segmented, and its timing in respect to the patterning of the flagellomeres, is relevant to the assessment of positional homology. This point is best illustrated with reference to an insect group in which the total number of antennomeres is largely but not universally fixed, as are the Coleoptera, most of which have antennae of 11 antennomeres. The extensive conservation of this number suggests that we can suppose an equally conserved segmentation process, thus a conservation of the relative positional value of the individual antennomeres. Under such circumstances, the fifth antennomere, for example, can be regarded as the same in all beetles with antennae of 11 antennomeres. Things are different when antennae with different number of antennomeres are compared. For example, how to trace homologies between the individual antennomeres of a 9antennomere beetle antenna and those of an antenna with the usual 11 antennomeres (Figure 1)? To answer the question we should know the sequence of events by which the flagellum acquires segmentation. Unfortunately, current knowledge about this process is very poor for the holometabolous insects, from both the morphological and genetic points of view.

A first difficulty to be addressed is the fact that the segmentation of the insect antenna occurs under different and not obviously comparable conditions. Important sequences of segmentation happen during formative stages, that is, either in the embryo or in the pupa, but in most non-holometabolous insects there is also a more overt phase of increase in the number of antennomeres during the post-embryonic development. Differences between embryonic or pupal antennal segmentation and postembryonic addition of antennomeres are not limited to the much easier access to the latter 
than to the former, but are also exacerbated by the widespread although implicit assumption that the post-embryonic segmentation of the antenna is fundamentally different from the embryonic or pupal one - whatever fundamental may eventually mean.

In this article, I suggest that the process of segmentation of the insect antenna (of its flagellum in particular) is to some extent the same irrespective of the time it occurs, in the framework of the animal's embryonic or post-embryonic development, except perhaps for the larval antenna of the holometabolans. Interpreting the differences in the segmentation of the antenna of all insects essentially as temporal (heterochronic) variations of one basic developmental theme will suggest i) a new framework for tracing homologies between antennomeres that is likely applicable to all insects (and possibly also to other arthropods, malacostracan crustaceans especially) and ii) a targeted research agenda on the mechanisms of antennal segmentation.

\section{Segmentation of the antenna in non-holometabolous insects}

In the majority of non-holometabolous insects, the process of segmentation of the antenna is partly embryonic, partly postembryonic. In other terms, the number of antennomeres generally increases also throughout the series of post-embryonic moults. The final number of antennomeres is fixed in some orders, variable in others, often with some degree of intraspecific variation, especially in antennae with dozen of flagellomeres.

The main source of new antennomeres is always the most proximal flagellomere, or meriston (Henson, 1947). This segment divides a variable number of times, thus giving off a series of offspring articles that are progressively pushed towards the distal end of the antenna. In most non-holometabolous insects, the divisions of the meriston are binary, but in the Mantophasmatodea the meriston divides five times into three flagellomeres at each time (Hockman et al., 2009).

The subsequent fate of the articles split off from the meriston is diverse. In some insect groups, these articles do not split anymore. For example, in the whole post-embryonic development of the Zoraptera there is only a binary division of the meriston with the moult from the second to the third instar (the total number of antennomeres growing this way from 8 to 9) and no further division of antennal articles will follow (Mashimo et al., 2014); similarly, none of the flagellomeres split off the meriston of the Mantophasmatodea undergoes subsequent splitting (Hockman et al., 2009). In other insects, the flagellomeres that split off from the meriston undergo further, but limited, splitting, often following stereotyped sequences, with some difference from group to group. For example, divisions of flagellomeres at various positions along the flagellum are observed, e.g., in the Blattodea (Schafer, 1973) and the Orthoptera. The sequence of post-embryonic segmentation of the locust Dociostaurus maroccanus (Thunberg, 1815) reconstructed by Paoli (1937) and reproduced as exemplary for hemimetabolans in Imms's (1940) classic paper on growth processes in the antennae of insects, is reproduced here (Figure 2), and interpreted in the light of the hypothesis presented in this article.

Insects, those with the longest antennae included, are arguably not the best arthropod group where to look for a model in which to study of the segmentation of the flagellum. Terminal flagella (Boxshall, 2004; 2013) are present, indeed, also in appendages of other taxa, for example in both the first and the second antennae of

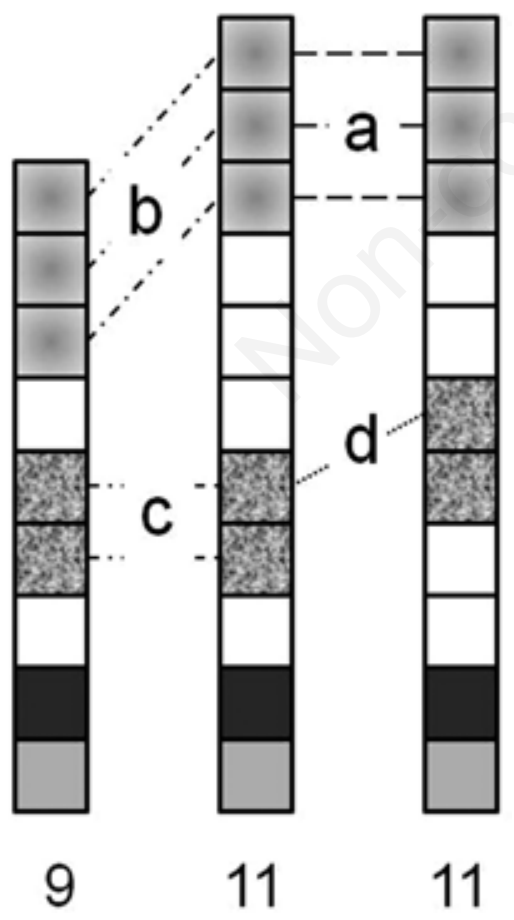

Figure 1. Positional homology between individual antennomeres of two insects is unambiguous when the total number of antennomeres is the same (a, homology; d, lack of homology), but problematic otherwise $(b, c)$.

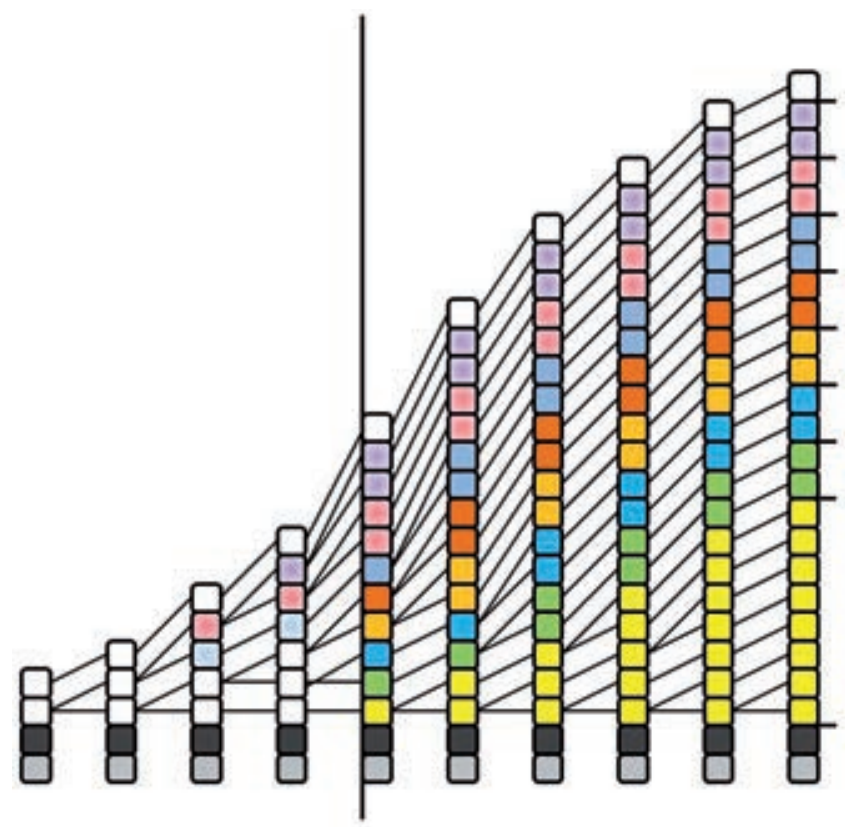

Figure 2, Segmentation of the antenna in Dociostaurus maroccanus, based on Paoli (1937) (part of the sequence to the right of the vertical line) and extrapolated into the embryonic phase of development (left of the vertical line) according to the model discussed in the text. Post-embryonic splits of flagellomeres are exactly as described; position and sequence of the embryonic ones are hypothetical. 
malacostracan crustaceans. In many isopods, in particular, the post-embryonic progression in the production of flagellomeres can be studied very easily because of the presence of a 2-segmental or 4-segmental periodicity in the distribution of specific morphological markers (setae, sensilla). Therefore, I introduce here briefly the (mainly post-embryonic) segmentation process in the second antenna of the isopod crustacean Asellus aquaticus (Linnaeus, 1758) (Maruzzo et al., 2007).

This appendage is composed of a proximal six-article peduncle (a fixed part formed by segments provided with musculature, like scape + pedicel of the insect antenna) and a distal flagellum divided into flagellomeres whose number increases during the whole life of the animal. After several moults, most of the flagellum is formed by a sequence of units of four articles (complete quartets) recognisable on the basis of a specific setal pattern. Throughout life, the meriston gives off apically a series of new articles, each of which is the potential founder of a quartet. A complete quartet is the product of three divisions occurring at subsequent moult in a strictly stereotyped sequence (Figure 3 ). At any time, the proximal part of the antenna (peduncle plus meriston) is followed by a variable number of still incomplete quartets (singletons first, followed by doublet and triplets), followed in turn by complete quartets, the number of which increases during postembryonic development, to end with an apical complex of few articles with invariable composition. Thus, i) new flagellomeres are formed in a strictly stereotype manner, ii) starting with quartet-founders sequentially split off from the meriston, and iii) a growing number of indivisible flagellomeres accumulates in the apical part of the antenna.

According to Maruzzo et al. (2008), this segmentation model is likely common to most of the aselloid isopods, except for the fact that some genera, e.g. Lirceus Rafinesque-Schmaltz, 1820, form doublets rather than quartets. The presence of a meriston as the sole ultimate source of new articles has been reported also for the valviferan isopods (Naylor, 1955; El Hedfi-Bel Haj Khelil, 2002) and other malacostracan crustaceans, e.g. the amphipod Gammarus chevreuxi Sexton, 1913 (Sexton, 1924) and the decapods Cherax destructor Clark, 1936 (Sandeman \& Sandeman, 1996) and Panulirus argus (Latreille, 1804) (Steullet et al., 2000). In some species, divisions in articles other than the first one have been reported, but it is still possible that the meriston is always the

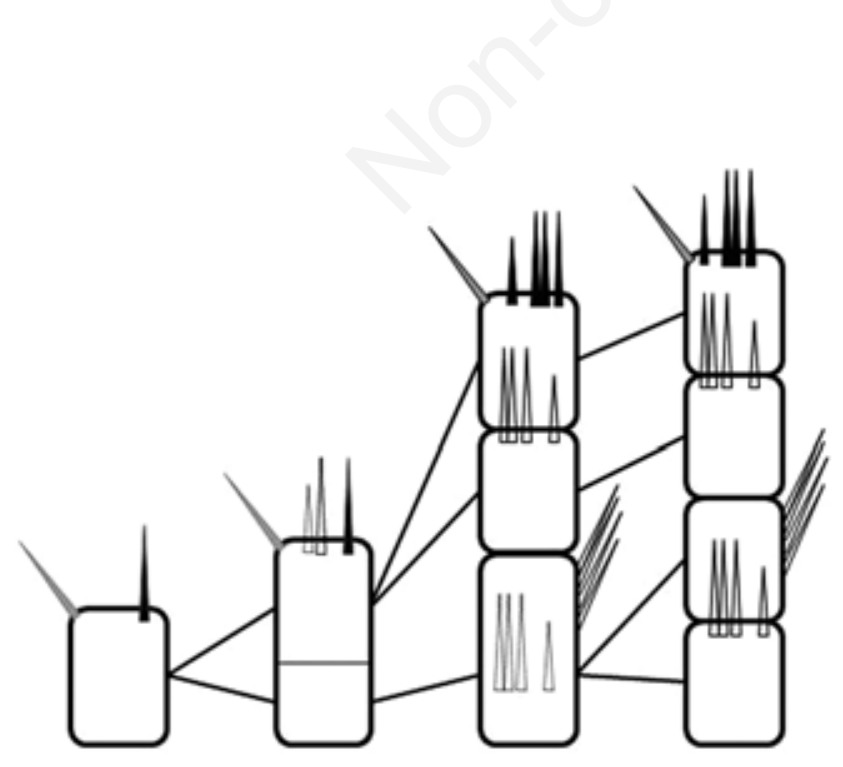

Figure 3. Splitting sequence of a primary flagellomere into four secondary flagellomeres in the isopod Asellus aquaticus (after Maruzzo et al., 2007, redrawn). ultimate origin of all flagellomeres, if the proximal flagellomeres other than the meriston that divide post-embryonically were split off from the meriston in an earlier phase, either embryonic or postembryonic, about which no evidence was collected.

In the first post-embryonic instar of Asellus, the periodic organization of the flagellum that will be more fully deployed following a number of moults is already delineated. This indicates that the process of segmentation of the flagellum is not affected by moving from the embryonic to the post-embryonic phase of the development. The same is arguably true for the nonholometabolous insects. When moving to the holometabolans, however, it is safe to start with the development of the adult antenna. I will briefly discuss the antenna of some insect larva in a later section of this article.

\section{Segmentation of the antenna in holometabolous insects}

Unfortunately, virtually nothing is known about the segmentation of the flagellum in the imaginal discs.

Some insights about this process can be obtained, however, by examining patterns and trends of variation in the end products of this process, that is, the variation in the number of flagellomeres (or in the total number of antennomeres) in different groups and also, when applicable, within a species.

A comprehensive review is beyond the scope of this article. I will thus focus onto the Coleoptera, for which I already provided (Minelli, 2005) a review of deviations from the usual number of 11 antennomeres and suggested an interpretation of the subdivision of the flagellum into multiple flagellomeres of which the model presented in this paper is a revised version, tentatively extended to all insects (Figure 4).

Antennae with less than 11 articles are much more common than those with 12 or more. In the previous paper (Minelli, 2005) I listed 46 families that include one or more species with 10 antennomeres, 31 with 9,22 with 8,12 with 7,4 with 6,4 with 5,2 with 4,5 with 3 and 2 with 2 . Some adjustments would be required by the inclusion of a few cases overlooked in that paper, or discovered subsequently, as well as by recent changes in the circumscription of a couple of families, but this would not change this trend, i.e., departure from 11 being increasingly infrequent with increasing reduction of antennomere number. Variation is extensive only in very few families or subfamilies, e.g. the Staphylinidae Pselaphinae, with all possible numbers between 2 and 11, and the Chrysomelidae, with 3 to 11, and also 12 . The number of antennomeres can be highly variable even within a genus, e.g. any number between 4 and 11 in Anthrenus Geoffroy, 1762 (Dermestidae) (Háva, 2004), between 3 and 7 in Acanthodes Baly, 1864 (Chrysomelidae) (Borowiec \& Świętojańska, 2014), between 7 and 9 in Anacaena Thomson, 1859 (Hydrophilidae) (Komarek \& Beutel, 2007), and even between strict relatives, e.g. Hycleus ringenbachi Bologna, 2009 with 9 antennomeres vs. H. silbermanni (Chevrolat, 1840) with 11, both also closely related to $H$. allardi (Marseul, 1870), where the number of antennomeres varies between 9 and 11 within the species (Bologna, 2009). Departures from the full number of 11 are also often accompanied by sexual dimorphism, e.g. in the subgenus Helocerus Mulsant \& Rey, 1868 of Anthrenus, with 5 antennomeres in the male and 6 in the female (Háva, 2004).

In comparisons between species with different numbers of antennomeres, the relative or absolute length of the proximal antennomeres is sometimes suggestive of genealogical relationships among flagellomeres. For example, in comparisons between 
specimens of Cycloneda lacrimosa González \& Vandenberg, 2006 (Coccinellidae) with different total number of antennomeres, antennomere III is much longer in specimens with 9 antennomeres than in those with 10 or 11 , and in specimens with 10 antennomeres antennomere IV is only slightly shorter than the sum of $\mathrm{IV}+\mathrm{V}$ in specimens with 11 antennomeres. Simply based on these metric relationships, González \& Vandenberg (2006) suggested that the first flagellomere is the source of (at least) antennomeres III, IV and V of an antenna with 11 articles. In a sense, this is what we expect from a meriston. However, this inference is based on dubious evidence, as indicated by comparisons involving other species of the same genus Cycloneda. For example, the third antennomere (first flagellomere) of Cycloneda eryngii (Mulsant, $1850)$ is approximately as long as the next three together, whereas in C. sicardi (Brèthes, 1925) it is only slightly longer than the fourth antennomere, nevertheless both species have a total number of 11 antennomeres.

Beetles with 12 antennomeres or more are quite rare (but there are many species with 12 antennomeres in the Cerambycidae) and are essentially restricted to a limited number of families representing two major lineages: i) Elateridae, Rhagophthalmidae, Lampyridae and Phengodidae, all belonging to the Elateroidea, plus the Rhipiceridae, belonging to the Dascilloidea, which are probably the sister group of the Elateroidea (Hunt et al., 2007); ii) Cerambycidae and Chrysomelidae, both Chrysomeloidea. A few species with 12 antennomeres are also known from the Scarabaeidae and the Anthribidae.

Within the Elateridae, the very few species with 12 antennomeres occur in three distinct clades (Casari, 2008). In the Rhagophthalmidae, males have 12 antennomeres, whereas the larviform females have only 6 or 7; in the Phengodidae, antennomeres are mainly 12 , but occasionally 11 or 10 . Stronger departures in excess of 11 are restricted to the Rhipiceridae Rhipicerinae and the Lampyridae.

The Rhipicerinae have more than 11 antennomeres, usually with intraspecific variation (e.g., 20-46 in Rhipicera reichei Guérin-Méneville, 1843) and higher number of antennal segments in the male. For example, Jin et al. (2013) list the following numbers: Polymerius Philippi, 1871 - male: 20, female: 18; Polytomus Dalman, 1819 - male: 23-32, female: 18-22; Oligorhipis GuérinMéneville, 1843 - male: 18-45, female: 17-21; Rhipicera Latreille, 1817 - male: 20-49, female: 18-29.

In the Lampyridae, high and variable number of antennomeres is found in Amydetes Illiger, 1807, with the majority of species having between 29 and 43 antennomeres (but not all numbers in this range have been recorded to date); in the specimens of
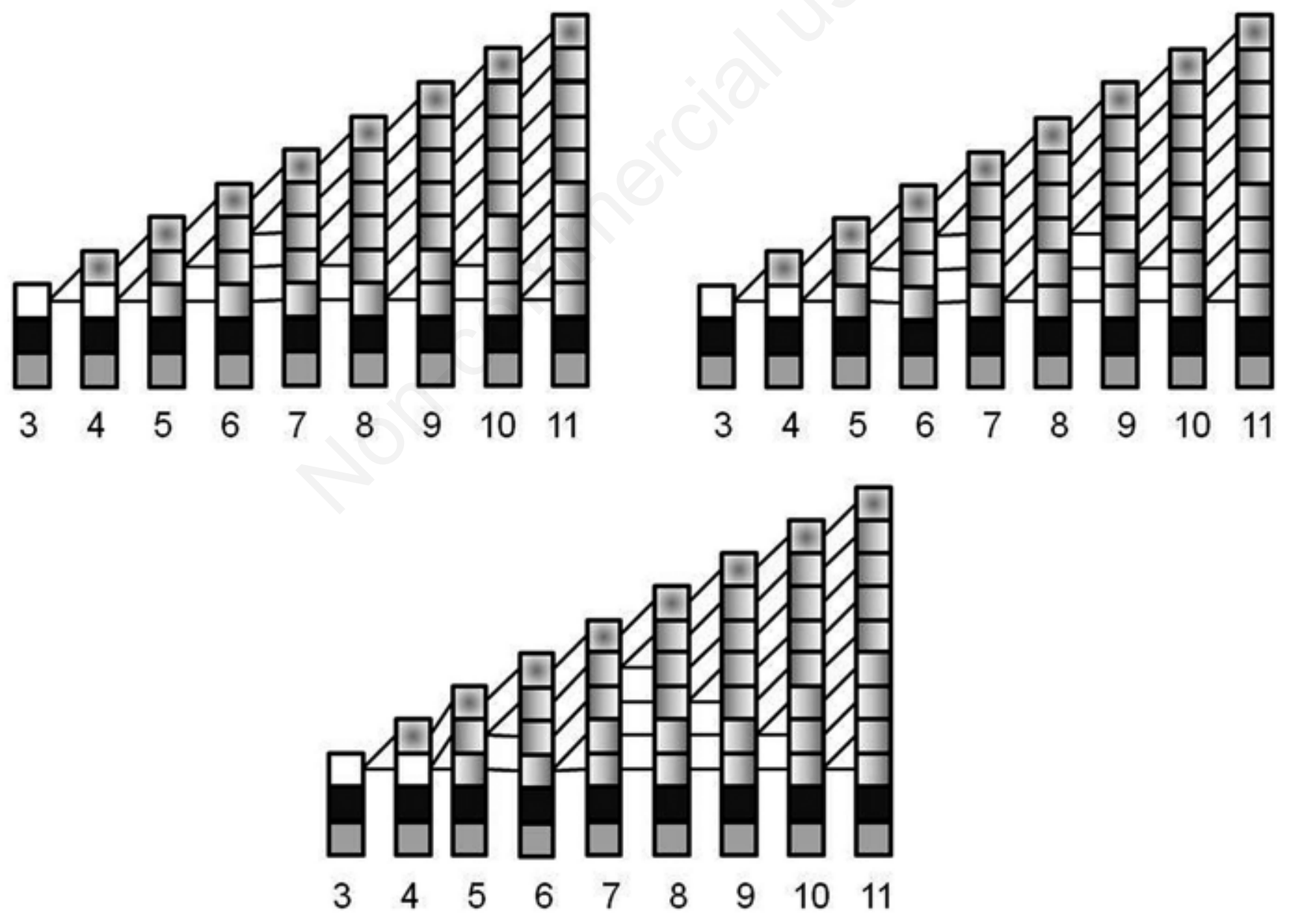

Figure 4. Hypothetical sequence of segmentation of the antenna of Coleoptera, based on Minelli (2005), modified. Three sequences are given, differing in the timing of secondary splitting of two primary antennomeres, but with a conserved sequence of splitting of each primary flagellomere into secondary flagellomeres, identical with the sequence observed in Asellus (Figure 3). 
Amydetes solaris Silveira \& Mermudes, 2014 recorded thus far, the numer of antennomeres is 61 or 62 (Silveira \& Mermudes, 2014). Most of the remaining genera of Lampyridae have 11 antennomeres, but also species with 6, 8, 9, 10, 12 and 15 have been recorded. Interestingly, there are two major discontinuities in the distribution of number of antennomeres, one between the nonAmydetes fireflies and the Amydetes with the lowest numbers of antennomeres, and another between the latter and A. solaris. Very roughly, the majority of Amydetes species have numbers approximately double in respect to the non-Amydetes fireflies with the highest numbers, and $A$. solaris has about twice as many antennomeres as the majority of the species in the genus. It is tempting to speculate that this pattern may reflect one or two runs of duplications, rather than different pulses of sequential generation of new flagellomeres from a single origin (tentatively, the most basal flagellomere, with the character of meriston).

In the Cerambycidae, more than 12 antennomeres are present in a few Cerambycinae and Prioninae (up to over 30 in the latter); in the same family, however, there are also a few taxa with reduced number of antennomeres (eight in the females of Allaiocerus Galileo, 1987 and Casiphia Fairmaire, 1894; nine in both sexes of Drumontiana Danilevsky, 2001 and in some Lamiinae (Svacha \& Lawrence, 2014)).

If variation is the number of antennomeres is to some extent matters of heterochrony, as suggested in the Introduction, it is possibly not by chance that deviations from the plesiomorphic and largely prevalent number of 11 antennomeres, in the Coleoptera, are frequent and conspicuous in the Elateroidea, a clade in which neoteny is frequent and occasionally accompanied by reduction in the number of antennomeres, as in the neotenic females of the Rhagophthalmidae and in some Lampyridae. Interestingly, in the (non neotenic) males of the Rhagophthalmidae the number of antennomeres is in excess of 11, as in the lampyrid genus Amydetes mentioned above, of which the likely neotenic females is, however, unknown.

Possibly in the same context it is to be explained the singular case of Drilus mauritanicus Lucas, 1842, a member of the Drilini, recently recognized as a derived, neotenic clade within the subfamily Agrypnini of the Elateridae (Kundrata et al., 2014). In this species the number of antennomeres is always 11 in the male, while in the female is variable, with 10 or 11 antennomeres of adult type, plus an additional terminal element. This rudimentary antennomere, bearing sensilla some of which are of larval type, is interpreted by Faucheux (2015) as a larval feature persisting in the adult, and manifesting the neotenic nature of the female.

Summing up, the distribution of number of antennomeres in the antennae of the adult Coleoptera is compatible with patterns of segmentation of the corresponding imaginal disc strictly equivalent to those manifested by the non-holometabolous insects, during the segmentation - partly embryonic, partly post-embryonic - of their antennae. A preliminary analysis of the antennae in other orders of holometabolous insects suggests a general conservation of segmentation mechanisms, with inter-and sometimes intraordinal differences comparable to those found among the non-holometabolans. A detailed comparative analysis will be presented elsewhere.

\section{Is the antenna of Heteroptera re-segmented?}

Irrespective of any degree of segmentation exhibited by the flagellum, the scape and the pedicel are remarkably conserved throughout the insects. Nevertheless, this conservation is probably not universal. Two possible exceptions are briefly discussed here. In either case, evidence is circumstantial only and the development of these antennae deserves accurate study in terms of both cellular mechanics and genetic control.

Of these two exceptions, one is provided by the larval antennae of some holometabolous insects and will be dealt with in the next section.

The other possible exception to the otherwise generalized conservation of the scape + pedicel + flagellum patterning of the insect antenna is provided by the Heteroptera. In this respect, the postembryonic antenna of most heteropteran subtaxa is quite uninformative: throughout the whole post-embryonic development, from the first nymphal stage to the adult, the number of antennomeres is uniformly four. The Pentatomidae, however, open a window into the segmentation of the antenna in these insects, and suggest resegmentation in respect to the scape + pedicel + flagellum pattern. In this family, indeed, the final moult is accompanied by the splitting of the second of the four articles, thus eventually producing the adult antenna of five antennomeres. This would be a unique case of subdivision of the pedicel, but I doubt that the second antennomere of the Heteroptera is actually a pedicel as inferred from its relative position.

Support in favour of a different interpretation is provided by the patterns of expression, in the embryonic antenna of Oncopeltus fasciatus (Dallas, 1852), of a set of genes known to be involved, in insects generally, in patterning the proximo-distal axis of the appendage, usually resulting in the articulation into scape, pedicel and flagellum. Oncopeltus belongs to the Lygaeidae, thus to a clade of the Heteroptera in which the antenna remains 4-segmented throughout the whole post-embryonic life. However, the pattern of gene expression we expect to find in a pentatomid is much more likely identical, or similar, to the pattern observed in Oncopeltus than to the pattern recorded from any of the few other insects for which corresponding evidence is available. Indeed, the spatial domain of expression of genes known to have a role of patterning the proximo-distal axis of insect appendages, of antennae in particular, is not the same in all insects.

Comparisons are possible (Angelini \& Kaufman, 2004) between Oncopeltus, Acheta domesticus (Linnaeus, 1758) (Orthoptera Gryllidae), Tribolium castaneum (Herbst, 1797) (Coleoptera Tenebrionidae) and Drosophila melanogaster Meigen, 1830 (Diptera Drosophilidae), despite the fact that the process occurs in two temporally and spatially different contexts, i.e. the embryonic antenna of Acheta and Oncopeltus vs. the antennal imaginal disc of Drosophila. The latter is subdivided into proximodistal domains corresponding to the scape, pedicel and flagellum, respectively, by the expressions of (and the epistatic relationships among) three major proximo-distal patterning genes, Distal-less, dachshund and homothorax (Dong et al., 2001).

In Oncopeltus, Acheta and Drosophila, the same genes, homothorax (hth) and Extradenticle (Exd), are expressed in the prospective scape, but at the level of the second antennomere only the expression of $h t h$ is common to the three insects; in addition, this region of the differentiating appendage continues to expresses Exd in Acheta, but expresses instead Distalless $(D l l)$ in Drosophila; same in Oncopeltus, but with the additional expression of dachshund (dac), a gene that in Drosophila is expressed instead in the prospective flagellum. In Tribolium, at metamorphosis, $h t h$ and Exd are expressed in the scape and the pedicel, Dll in the flagellum only (Smith et al., 2014); the expression of $d a c$ is limited to a number of proximal flagellomeres, but this gene is not expressed in the pedicel (Angelini et al., 2009), same as in Drosophila.

It is thus possible that, in terms of genetic control, the identity of the second antennomere (and, by implication, also the identity of the next one) is not necessarily the same throughout the insects. 
The expression of both $h t h$ and $d a c$ in what will develop into the second antennomere of Oncopeltus suggests that this article shares traits of the pedicel plus traits of the (first article of) the flagellum. If this interpretation is correct and can be generalized to the whole clade of the Heteroptera, this might help explaining the unique behaviour of this article in the Pentatomidae: if its position as the second antennomere, next to the scape, suggests that it is the pedicel, the division it undergoes with the moult to adult suggests instead a flagellar identity - and it may actually share both.

A circumstantial remark, whose weight per se would be very small, but may raise in significance when seen in the context of previous considerations, is the fact that in the Heteroptera the second antennomere is unusually long, in contrast with its size and conspicuousness in insects generally. The opposite trend is indeed much more widespread, the pedicel being sometimes minute and largely concealed within the distal part of the scape, e.g. in beetles such as paussine Carabidae, Gyrinidae, Collops Erichson, 1840 (Melyridae Malachiinae), Aspidytes Ribera, Beutel, Balke \& Vogler, 2002 (Aspidytidae) and the diminute Satonius kurosawai (Sato, 1982) (Torridincolidae) (Lawrence et al., 2011). Miniaturization per se has a limited effect on the segmentation of insect antennae (Polilov, 2015). Exceptions to this rule are generally unremarkable: in some genera of Ptiliidae and Corylophidae, to take the examples once more from the Coleoptera, the number of antennomeres in the adult is reduced from 11 to 8 , in agreement with its diminute size (Sorensson, 1997; Bowestead, 1999; Hall, 1999). However, at least in one extreme case, even the basic articulation into scape, pedicel and flagellum is completely obliterated: this happens in the tiny males of the mymarid hymenopteran Dicopomorpha echmepterygis Mockford, 1997, only $139 \mu \mathrm{m}$ long, whose antenna is reduced to one antennomere only (Mockford, 1997).

\section{Larval antennae}

As said before, the basic patterning into scape, pedicel and flagellum is also lacking, or problematic at least, also in the larval antennae of a number of holometabolous insects. I will not discuss here those larvae the antenna of which is either absent (e.g., many Diptera) or represented by one segment only (e.g., most of the Curculionidea among the Coleoptera), because in these instances either the scape or the pedicel, or both, are absent or at least lack individual identity. Additionally, we cannot assume a priori that in all larval antennae with 2 antennomeres these are actually the scape and the pedicel. I take here some examples from beetle antennae with three antennomeres at least, with their segmental interpretation as given by Lawrence (1991).

The 4-segmented antennae of the majority of species in the Cupedidae (one of the few families of the basal suborder Archostemata) and the vast majority of the Adephaga, with an increment in respect to the 3 antennomeres found in the larval antenna of the majority of beetles families, is attributed to a division of the first article, as suggested by the position of sensory structures; moreover, in the cupedid Distocupes varians (Lea, 1902) the antenna is 3-segmented in the first instar, but 4 resp. 5 and 6 segments are present in the subsequent instars, caused by divisions that apparently affect the first article again (Neboiss, 1968). The same interpretation is offered for the 4-segmented antenna of some Aphodiinae among the Scarabaeoidea; more complex patterns of segmentation are suggested for those Dytiscidae where the number of larval antennomeres is higher than 4. In some Phalacridae (Phalacrus, Phalacropsis) the larval antenna is 3-segmented, but the basal segment has been apparently suppressed, whereas the apical one is divided into 2 segments
(Steiner, 1984). Incomplete separation of the second and third segments is described for the larval antennae of a number of beetles belonging to different families. Whether or not the antennal segments described as the scape or the pedicel in all these larvae actually correspond to the segments so named in the adult, except for their position, deserves closer scrutiny with special regard for the patterns of expression of the usual appendage patterning genes ( $h t h$, Dll etc.).

Larval and adult antenna of the holometabolous insects are possibly (always?) temporal serial homologues, in the sense of Paulus (1989) who, for the eye of Chaoborus Lichtenstein, 1800 (Diptera Chaoboridae), demonstrated that a common anlage is responsible for the production of both larval stemmata and adult ommatidia. In that system, the visual organ precursors develop serially in two main waves, in two different developmental contexts (embryonic/larval, producing stemmata, and pupal/adult, producing ommatidia). If larval and adult antenna similarly derive from parts of the same embryonic anlage, what exactly does the larval antenna represent? More precisely, does it actually include (when at least 3 antennomeres are present) elements corresponding to scape, pedicel and flagellum? At present, one can only speculate on that.

\section{Summary and prospects}

Summing up, the basic mechanism by which the antennal flagellum is subdivided into a variable number of flagellomeres is probably the same in all insect, irrespective of whether the process occurs, in part or wholly, in the embryo, in the eye/antenna imaginal disc, or through a series of post-embryonic increments punctuated by moults. The increase in the number of antennomeres does not occur by terminal addition, but in intercalary fashion, in two main cycles which are, in turn, distinguishable only in terms of the relative position of the antennomere undergoing division. The ultimate origin of (all?) flagellomeres is the meriston, the first antennomere following the pedicel, from which split off in apical direction new primary flagellomeres, each of which is eventually the source of secondary flagellomeres, according to a spatial and temporal pattern specific to a more or less extended clade.

Different numbers of flagellomeres are obtained by temporal modulation of this process (heterochrony). This is obtained at different levels:

- the meriston may terminate divisions more or less in advance of the last moult, or continue to divide so long as the insect moults;

- the divisions of the meriston are very often binary, in pace with the moults; however, the divisions may proceed at a higher pace than the moulting cycle, as in the Mantophasmatodea, where the divisions of the meriston are ternary;

- the eventual splitting of the primary flagellomeres into secondary flagellomeres is likely to follow a stereotyped sequence, as in the asellote isopods; targeted research will show if, and how, there is scope for heterochrony also at this level;

- primary flagellomeres, if further dividing, are likely to start their cycle of secondary segmentation in the same temporal sequence as the temporal order in which they have split off from the meriston; this does not rule out, however, variation in the overall sequence of splitting events, depending on the delay by which the primary flagellomeres start their segmentation cycle and the timing of the secondary divisions (Figure 4).

The apical antennomere is unlike to divide. Putative exceptions (e.g., Cerambycidae with 12 antennomeres; Svacha \& Lawrence, 2014) deserve closer study. 
As noted above, this parsimonious hypothesis in the light of which the segmentation of the insect flagellum is an essentially uniform process throughout the whole group implies that otherwise momentous events such as the transition from the embryonic to the post-embryonic phase of development, or the moulting events, do not really interfere with the process of segmentation of the appendage, but only mark a series of steps along this process.

To go back to the question with which I opened this article, statements of positional homology between flagellomeres of the antennae of two individuals or species are likely to be unambiguous (although not necessarily so) when both antennae have the same number of antennomeres. However, when numbers are different, only a detailed knowledge of the underlying segmentation processes would provide the ultimate background for determining positional homology; eventually, this will often necessitate to move from a naif search for a one-to-one correspondence to the acknowledgement that a given article in an appendage with a lesser number of antennomeres may correspond to a small number of contiguous articles in an appendage with higher total number of antennomeres.

For the reason discussed in the previous sections, it is quite possible that the larval antennae of the holometabolans and the antennae of the Heteroptera do not fit completely within the general model outlined here: more obvious in the first case, but also probable - for different reasons and to a different extent - in the other. These antennae are probably evolutionary novelties that deserve priority study. But the model outlined in this paper suggests also a number of questions to be addressed in respect to the other, putatively less derived antennae. Significant progress would be done by understanding what differentiates antennomeres that divide, either embryonically or post-embryonically, from those that do not; and by discovering whether the spatial and temporal pattern of division along the flagellum depends on local cues, or on signals travelling along the whole proximo-distal axis of the appendage.

\section{References}

ANGELINI D.R., KAUFMAN T.C., 2004 - Functional analyses in the hemipteran Oncopeltus fasciatus reveal conserved and derived aspects of appendage patterning in insects. - Dev. Biol. 271: 306-321.

ANGELINI D.R., KIKUCHI M., JOCKUSCH E.L. 2009 - Genetic patterning in the adult capitate antenna of the beetle Tribolium castaneum. - Dev. Biol. 327: 240-251.

BOLOGNA M.A., 2009 - The Meloidae (Coleoptera) of Lybia: an annotated catalogue and description of three new species. Ann. Soc. Entomol. Fr. 45: 345-364.

BOROWIEC L., ŚWIĘTOJAŃSKA J., 2014 - Cassidinae Gyllenhal, 1813. In: LESCHEN R.A.B., BEUTEL R.G. (Eds.) Coleoptera, Beetles. Volume 3. Morphology and Systematics (Phytophaga): 198-217. - De Gruyter, Berlin/New York.

BOWESTEAD S., 1999 - A revision of the Corylophidae (Coleoptera) of the West Palaearctic region. Instrum. Biodivers. 3. - Geneva: Mus. Hist. Nat.

BOXSHALL G.A., 2004 - The evolution of arthropod limbs. Biol. Rev. 79: 253-300.

BOXSHALL G.A., 2013 - Arthropod limbs and their development. In: MINELli A., BOXSHALL G., FUSCO G. (Eds.). Arthropod biology and evolution: Molecules, development, morphology. - Springer, Berlin: 241-264.
CASARI S.A., 2008 - Cladistic analysis of Hemirhipini with establishment of Propalaus gen. nov. (Coleoptera, Elateridae, Agrypninae). - Papéis Avulsos de Zoologia 48: 139-180.

DONG P.D.S., CHU J., PANGANIBAN G., 2001 - Proximodistal domain specification and interactions in developing Drosophila appendages. - Development 128: 2365-2372.

EL HEDFI-BEL HAJ KHELIL C., 2002 - Développement postembryonnaire chez Synisoma nadejda Rezig, 1989 (Isopoda, Valvifera). - Crustaceana 75: 841-848.

FAUCHEUX M.J., 2015 - Persistence of larval characteristics on the antennae of the neotenic female of Drilus mauritanicus Lucas, 1849 (Coleoptera, Elateridae, Agrypninae, Drilini). Bull. Inst. Sci. Rabat, Sci. Vie 36.

GONZÁLEZ G., VANDENBERG N.J., 2006 - Review of lady beetles in the Cycloneda germainii species complex (Coleoptera; Coccinellidae: Coccinellinae: Coccinellini) with descriptions of new and unusual species from Chile and surrounding countries. - Zootaxa 1311: 13-50.

HALL W.E., 1999 - Generic revision of the tribe Nanosellini (Coleoptera: Ptiliidae: Ptiliinae). - Trans. Am. Entomol. Soc. 125: 39-126.

HÁVA J., 2004 - World keys to the genera and subgenera of Dermestidae (Coleoptera), with descriptions, nomenclature and distributional records. Acta Mus. Nat. Pragae, Ser. B, Hist. Nat. 60: 149-164.

HENSON H., 1947 - The growth and form of the head and antennae in the earwig (Forficula auricularia Linn.). Proc. Leeds Phil. Lit. Soc. (Sci. Sect.) 5: 21-32.

HOCKMAN D., PICKER M.D., KLASS K.D., PRETORIUS L., 2009 - Postembryonic Development of the unique antenna of Mantophasmatodea (Insecta). - Arthropod Struct. Dev. 38: 125-133.

HUNT T., BERGSTEN J., LEVKANICOVA Z., PAPADOPOULOU A., JOHN O. S., WILD R., HAMMOND P. M., AHRENS D., BALKE M., CATERINO M. S. GÓMEZZURITA J., RIBERA I., BARRACLOUGH T.G., BOCAKOVA M., BOCAK L., VOGLER A.P., 2007 - A comprehensive phylogeny of beetles reveals the evolutionary origins of a superradiation. - Science 318: 1913-1916.

IMMS A.D., 1940 - On growth processes in the antennae of insects. - Quart. J. Microsc. Soc. 81: 585-593.

JIN Z., ESCALONA H.E., SLIPINSKI A., PANG H., 2013 Phylogeny and classification of Rhipicerinae (Coleoptera: Rhipiceridae) with a review of the Australian taxa. - Ann. Zool. 63: 275-317.

KOMAREK A., BEUTEL R.G., 2007 - Phylogenetic analysis of Anacaenini (Coleoptera: Hydrophilidae: Hydrophilinae) based on morphological characters of adults. - Syst. Entomol. 32: 205-226.

KUNDRATA R., BOCAKOVA M., BOCAK L., 2014 - The comprehensive phylogeny of the superfamily Elateroidea (Coleoptera: Elateriformia). - Mol. Phyl. Evol. 76: 162-171.

LAWRENCE J.F., 1991 - Order Coleoptera. In: STEHR F.E. (ed.) Immature insects, vol. 2. - Kendall/Hunt Publ., Dubuque: 144298.

LAWRENCE J.F., SLIPINSKI A., SEAGO A.E., THAYER M.K., NEWTON A.F., MARVALDI A.E., 2011 - Phylogeny of the Coleoptera based on morphological characters of adults and larvae. - Ann. Zool. 61: 1-217.

MARUZZO D., EGREDZIJA M., MINELLI A., FUSCO G., 2008 - Segmental pattern formation following amputation in the flagellum of the second antennae of Asellus aquaticus (Crustacea, Isopoda). - It. J. Zool. 75: 225-231.

MARUZZO D., MINELLI A., RONCO M., FUSCO G., 2007 - 
Growth and regeneration of the second antennae of Asellus aquaticus (Crustacea, Isopoda) in the context of arthropod antennal segmentation. - J. Crust. Biol. 27: 184-196.

MASHIMO Y., BEUTEL R.G., DALLAI R., LEE C.Y., MACHIDA R., 2014 - Postembryonic development of the ground louse Zorotypus caudelli Karny (Insecta: Zoraptera: Zorotypidae). - Arthr. Syst. Phyl. 72: 55-71.

MINELLI A., 2005 - A segmental analysis of the beetle antenna. Studi Trentini, Acta Biol. 81: 91-101.

MOCKFORD E.L., 1997 - A new species of Dicopomorpha (Hymenoptera: Mymaridae) with diminutive, apterous males. Ann. Entomol. Soc. Am. 90: 115-120.

NAYLOR E., 1955 - The comparative external morphology and revised taxonomy of the British species of Idotea. - J. Mar. Biol. Ass. UK 34: 467-493.

NEBOISS A., 1968 - Larva and pupa of Cupes varians Lea, and some observations on its biology. - Mem. Nat. Mus. Victoria 28: $17-19$.

PAOLI G., 1937 - Studi sulle cavallette di Foggia (Dociostaurus maroccanus Thnb.) e sui loro oofagi (Ditteri Bombiliidi e Coleotteri Meloidi) ed acari ectofagi (Eritreidi e Trombidiidi). - Redia 23: 27-202.

PAULUS H.F., 1989 - Das Homologisieren in der Feinstrukturforschung: das Bolwig-Organ der höheren Dipteren und seine Homologisierung mit Stemmata und Ommatidien eines ursprünglichen Fazettenauges der Mandibulata. - Zool. Beitr. N.F. 32: 437-478.

POLILOV A.A., 2015 - Small is beautiful: features of the smallest insects and limits to miniaturization. - Annu. Rev. Entomol. 60: 103-121.

SANDEMAN R.E., SANDEMAN, D.C., 1996 - Pre- and postembryonic development, growth and turnover of olfactory receptor neurones in crayfish antennules. - J. Exp. Biol. 199: 2409-2418.

SCHAFER R., 1973 - Postembryonic development in the antenna of the cockroach, Leucophaea maderae: growth, regeneration, and the development of the adult pattern of sense organs. - J. Exp. Zool. 183: 353-364.

SEXTON E.W., 1924 - The moulting and growth-stages of Gammarus, with description of the normals and intersexes of G. chevreuxi. - J. Mar. Biol. Ass. UK 13: 340-401.

SILVEIRA L.F.L., MERMUDES J.R.M., 2014 - Systematic review of the firefly genus Amydetes Illiger, 1807 (Coleoptera: Lampyridae), with description of 13 new species. - Zootaxa 3765: 201-248.

SMITH F.W., ANGELINI D.R., JOCKUSCH E.L., 2014 - A functional genetic analysis in flour beetles (Tenebrionidae) reveals an antennal identity specification mechanism active during metamorphosis in Holometabola. - Mech. Dev. 132: 13-27.

SORENSSON M., 1997 - Morphological and taxonomical novelties in the world's smallest beetles, and the first OldWorld records of Nanosellini. - Syst. Entomol. 22: 257-283.

STEINER W.E. Jr., 1984 - A review of the biology of phalacrid beetles (Coleoptera). In: Q. WHEELER Q., BLACKWELL M. (Eds.). Fungus-insect relationships: perspectives in ecology and evolution. - Columbia University Press, New York: 424-445.

STEULLET P., CATE H.S., DERBY C.D., 2000 - A spatiotemporal wave of turnover and functional maturation of olfactory receptor neurons in the spiny lobster Panulirus argus. - J. Neurosci. 20: 3282-3294.

SVACHA P., LAWRENCE J.F., 2014 - Cerambycidae Latreille, 1802. In: LESCHEN R.A.B., BEUTEL R.G. (Eds.) Coleoptera, Beetles. Volume 3. Morphology and Systematics (Phytophaga). De Gruyter, Berlin/New York: 77-177. 